\title{
Dentine Hypersensitivity: A Review
}

\section{Najat Bubteina ${ }^{1 *}$ and Sufyan Garoushi' ${ }^{2,3}$}

${ }^{1}$ Department of Conservative Dentistry, Faculty of Dentistry, Benghazi University, Libya

${ }^{2}$ Department of Restorative Dentistry and Periodontology, School of Dentistry, Libyan International Medical University, Libya

${ }^{3}$ Department of Biomaterials Science and Turku Clinical Biomaterials Center (TCBC), Institute of Dentistry, University of Turku, Finland

\begin{abstract}
Dentine hypersensitivity (DHS) is a wide spread painful dental problem that is characterized by short sharp pain arising from exposed dentin in response to several different stimuli. This accepted definition, indicates the need to consider a differential diagnosis to rule out other causes of dental pain before the diagnosis of dentin hypersensitivity is made. The management strategy of this dental problem required a good understanding of the complexity of the condition and the variety of the treatment options. The aim of this review is to inform practitioners about dentin hypersensitivity, to provide a brief overview of the diagnosis, etiology and clinical management of dentin hypersensitivity. We have used PubMed to find relevant literature published up to date. We used combinations of key words like hypersensitivity, dentine, desensitize and dental pain.
\end{abstract}

Keywords: Dentine hypersensitivity; Etiology; Mechanism of sensitivity; Diagnosis; Treatments

\section{Introduction}

Dentine hypersensitivity (DHS) is one of the most commonly encountered dental problems. It is characterized by short, sharp pain arising from exposed dentine in response to stimuli, typically thermal, evaporative, tactile, osmotic or chemical and which cannot be ascribed to any other dental defects or pathology [1]. Hypersensitivity may present on several teeth, in one area of the mouth, or on one specific tooth $[2,3]$. DHS should be differentiated from other tooth sensitivity which may elicit from other clinical conditions such as dental caries, microleakage, cracked tooth or fractured restorations [4]. The clinical management of DHS has been a challenge for clinician, various treatment modalities are available, but the success of any sound treatment plan is depended on taking a detailed clinical and dietary history, differentially diagnose the condition from other dental pain conditions and identify and manage etiological and predisposing factors [5-8].

Since then, several authors have used others terms to describe DHS by replacing the word dentine, adding site descriptors, such as cervical or root, and joining this with either hypersensitivity or sensitivity. This practice resulted in a significant number of variations to describe the apparently same condition [4]. In 2003 the Canadian Advisory Board on DHS recommended that the use of term disease instead of term pathology will be more accurate and correct [9]. This definition provides clinical descriptor of the condition and identifies DHS as distinct entity hence; it encourages the clinician to consider a differential diagnosis [5]. Since there are many other conditions that are well known to produce symptoms similar to that of dentine pain, the clinician should exclude other possible causes of pain before proceeding with any treatment modalities of DHS because such conditions may require different treatment options that are different from those used for DHS. Such conditions include chipped enamel, fractured restoration, caries, marginal leakage of restorations, cracked cusps of teeth and even palate-gingival grooves $[4,10]$.

\section{Prevalence and epidemiology}

Various studies showed that the incidence of DHS in most populations ranges between $10-30 \%$ of the general population and the age range varies from 20-50 years with the peak incidence occurring at the end of the third decade and decreases during the fourth and fifth decades oflife [11-13]. These variations were conducted to the differences in populations, habits, dietaries, and methods of investigations which are usually patient questionnaires or clinical examinations [14-16]. The higher incidence of DHS is reported in females than in males which may reflect hormonal influence and dietary practices $[12,17,18]$. In contrary, one study showed no difference in prevalence of dentine hypersensitivity in either gender, suggesting overall that as many males as females are susceptible [17]. Concerning the type of teeth involved, canines and premolars of both the arches are the most affected teeth. Also it was reported that buccal aspect of cervical area is the commonly affected site [18].

\section{Theories and Mechanism of Sensitivity}

Several theories have been proposed over more than a century to explain the mechanism involved in dentine hypersensitivity [19]

\section{Odontoblastic transduction theory}

The odontoblast transducer theory proposed by Rapp et al. postulated that odontoblasts act as receptor cells, and transmit impulses via synaptic junctions to the nerve terminals causing the sensation of pain from the nerve endings located in the pulpodentine border [20]. However, evidence for the odontoblast transducer mechanism theory is deficient and unconvincing. This is because the majority of studies have shown that odontoblasts are matrix forming cells and they are not considered to be excitable cells, and no synapses have been revealed between odontoblasts and nerve terminals [21].

\section{Neural theory}

This theory advocated that thermal, or mechanical stimuli, directly affect nerve endings within the dentine tubules through direct communication with the pulpal nerve endings [20]. Although this theory has been reinforced by the presence of unmediated nerve fibers in the outer layer of root dentine [22] and the presence of putative

${ }^{*}$ Corresponding author: Dr. Najat Bubteina, Associate Professor, Department of Conservative Dentistry, Institute of Dentistry, Benghazi University, Libya, Tel: 00218 923967435; E-mail: nagat_bub@yahoo.com

Received August 10, 2015; Accepted August 24, 2015; Published September 04, 2015

Citation: Bubteina N, Garoushi S (2015) Dentine Hypersensitivity: A Review. Dentistry 5: 330. doi:10.4172/2161-1122.1000330

Copyright: () 2015 Bubteina N, et al. This is an open-access article distributed under the terms of the Creative Commons Attribution License, which permits unrestricted use, distribution, and reproduction in any medium, provided the original author and source are credited. 
neurogenic polypeptides [23], it is still considered theoretical with lack of solid evidences to support it.

\section{Hydrodynamic theory}

The currently accepted mechanism of dentine hypersensitivity is the hydrodynamic theory which has been proposed by Brännström in 1964 [24]. According to this theory, when the exposed dentin surface is subjected to thermal, chemical, tactile or evaporative stimuli, the fluid flow within the dentine tubules there will be increased [24]. This fluid movement within the dentine tubules causes an alteration in pressure and excites pressure-sensitive nerve receptors across the dentine. So the response of the excited pulpal nerves, mainly in intradentine fibers, will be depended upon the intensity of stimuli in pain production [25]. Scanning electron microscopic (SEM) examination of hypersensitive dentin surface reviles the presence of widely open dentine tubules which is considered consistent with the hydrodynamic theory [26]. Accordingly, the number and the diameter of the dentine tubules are considered important factors in initiating pain from DHS [26,27]. Hence, the higher the number and greater the diameter of the open dentine tubules the more intense will be the pain from DHS. It has been noted that triggers such as cold stimuli stimulate fluid to flow away from the pulp creating more rapid and rigorous neural responses than heat stimuli, which cause somewhat sluggish fluid flow towards the pulp [26-28]. This is aligned with the observation that dentine hypersensitivity patients are more frequently complain of pain in response to cold stimuli than to heat [29].

\section{Etiology of Dentine Hypersensitivity}

Dentin is covered by enamel in the crown region and by cementum in the radicular region. When the enamel or cementum is removed, the underlying dentin will be exposed along with the dentine tubules, producing dentin hypersensitivity. It has been postulated that DHS develops in two phases namely lesion localization and lesion initiation [16]. Lesion localization occurs by loss of protective covering over the dentin, thus exposing it to external environment. Lesion initiation occurs after the protective covering of smear layer is removed, leading to exposure and opening of dentine tubules. Evidence already showed that the lesions of DHS have many more and wider open tubules than do non sensitive dentin $[3,26,28]$.

Various studies have pointed out that dentin exposure may result in anatomic characteristics in the area of the enamel/cementum junction and/or enamel, or cementum loss due to one or more of the following processes [30,31]

\section{Gingival recession}

Gingival recession is usually recognized in patients with a high level of oral hygiene standards and in those who have poor level of oral hygiene. The causes of gingival recession in the population having good oral hygiene are due to overzealous tooth brushing, improper brushing technique or using of an excessive brushing forces and it is frequently seen on the buccal surfaces of the teeth [32]. On other hand, lack of tooth brushing, with consequent accumulation of dental plaque on root surfaces in patients with bad oral hygiene may lead to periodontal complications and migration of the gingiva in the apical direction, exposing the cementum and then to demineralization of tooth structures which could be associated with patency of dentine tubule orifices causing DHS [33,34]. Gingival recession is also a common side-effect of a periodontal treatment either surgical or nonsurgical one due to loss of attachment of healthy gingival tissue [35].

\section{Tooth wear}

It is considered an alternative pathway of cervical dentin exposure in the coronal aspect of the tooth due to the loss of dental hard tissue, especially enamel. It involves loss of enamel surface by attrition, abrasion, erosion or abfraction $[1,4,6,7,36]$.

Attrition is the loss of tooth substance or a restoration caused by tooth-to-tooth contact between opposing occluding or adjacent proximal surfaces as a result of parafunctional habits such as bruxism. Abrasion is the loss of tooth substance caused by factors other than tooth contact as in case of the over-vigorous use of a tooth brush, or the consumption of abrasive and fibrous diets.

Erosion is the progressive loss of hard dental tissues by chemical processes or acids not produced by cariogenic bacteria as in case of acidic agents associated with regurgitation or extrinsic acids associated with dietary and medication sources. Repeated exposures to low $\mathrm{pH}$ oral fluids lead to dissolution of the mineral content in the superficial layer of enamel, the result of which is loss of that tissue with consequent changes in tooth architecture. Inescapable dentine exposure results in dentin hypersensitivity. Abfraction lesions are wedge shaped defects developed at the cervical region of teeth and are not directly related to the diet, periodontal disease or abrasion [37]. They occur as a result of mechanical overloading of cervical enamel regions initiated by cuspal flexure and occlusal overloading, resulting in fracture of the enamel crystals in this area with subsequent exposure of the underlying dentin $[36,37]$.

\section{Other factors}

Some physiological causes that may consider as predisposing factors to DHS are the increase in the number of teeth with root exposure due to age advances, and tooth extrusion due to the nonexistence of an antagonist tooth. Once the root is exposed, the protective layer of cementum is easily removed, resulting in open dentin tubules [38].

\section{Assessment of DHS}

Traditionally DHS has been evaluated on the basis of the individual response to the presenting stimulus which could be in the form of verbal rating, visual analogue scales and questionnaires $[8,30,39]$.

Commonly, DHS might either be assessed in terms of a stimulus intensity required to elicit pain called stimulus-based assessment or as a subjective evaluation of the pain caused by a distinct stimulus named response-based assessment [39-41].

The stimulus-based assessments depend on the measurement of an individual pain threshold on which the subject's response is held constant at the pain threshold, and the stimulus is varied with increasing and decreasing intensities [39-41]. Different devices have been used in these methods such as a calibrated probe where the tactile pressure applied to the tooth with a dental explorer tip can be varied and increased in steps of $10 \mathrm{~g}$ increments until the patient experienced discomfort [41-43]. Alternative thermal or electrical devices such as electrical pulp testers, dental pulp stethoscope and others have been used for applying graded thermal or electrical stimuli [42]. It was realized that, these stimulus-based methods have certain drawbacks such as repeated painful stimulation may cause a change in sensitivity and influence the outcome. Furthermore, it was reported that stimulusbased methods are often time consuming, which limit the number of teeth that can be tested with multiple stimuli in one appointment [44].

On the other hand, the response-based methods assess pain severity after application of a constant, standardized, consistent, and 
reproducible stimulus like a timed airblast. The air will be directed for $1 \mathrm{~s}$ from a distance of approximately $1 \mathrm{~cm}$ at the exposed buccal surface of the hypersensitive tooth after its isolation from the adjacent teeth $[8,45]$. Directly after stimulation, the subject response can be quantified by using a verbal rating, or visual analog scales or a validated graphic pain scale, such as the Faces Pain Scale [8,45-47]. Several studies recommended the use of the Schiff cold air sensitivity scale to assess subject response to a stimulus like air or evaporative [48-50]. This scale is composed of several distinct scores which are:

i. Subject does not respond to air stimulus.

ii. Subject responds to air stimulus but does not request discontinuation of stimulus.

iii. Subject responds to air stimulus and requests discontinuation or moves from stimulus.

iv. Subject responds to air stimulus, considers stimulus to be painful, and requests discontinuation of the stimulus.

Recently, it was reported that the reproducibility of assessment methods of DHS was hard to achieve, even if standardized techniques were used [44]. Hence it was recommended that the outcome evaluation of DHS treatment in clinical practice as well as in clinical trials should comprise at least two different stimuli, and to use both assessment methods which are stimulus- and response-based assessments [8].

\section{Verbal rating scales}

For measuring of DHS, verbal rating scales (VRS) are used to grade the level of pain experience. Most pain scales utilize several pain descriptors, including 'no pain', 'weak', 'mild', 'moderate, 'strong', 'intense', and 'agonizing'. Numerical scores ( $0,1,2$, 3, etc.) have been attached to these descriptors, and mean values are calculated [8]. However, the mathematical interpretation of the scoring system has been challenged, in that the scores are often arbitrarily assigned numerical values, and the assigned scores are analyzed as if these numbers reflected true quantitative differences in pain rather than simple qualitative differences [39]. Hence the main disadvantage of verbal descriptor scales is that they could be restrictive because they may not offer enough descriptions that can be placed in a continuous and ascending or descending order of severity of pain [42].

\section{Visual analogue scale}

The visual analogue scale (VAS) utilizes a line of $10 \mathrm{~cm}$ length anchored at the 2 extremes with descriptors representing the absolute minimum and the absolute maximum of pain a patient can experience from an external stimulus [45]. It was designed to overcome the shortcomings of VRS [46]. In VAS assessments, the patient is asked to mark off the line such that it corresponds to the severity of the perceived pain and the pain intensity can be shown as an absolute value or as a percentage of the maximum [45].

\section{Objective evaluation}

This evaluation may include application of thermal and evaporative stimuli such as a short blast of cold air from the 3-in-1 syringe, mechanical or tactile stimuli such as running a sharp explorer over the area of exposed dentine or chemical stimuli such as using hypertonic solutions $[6,30,51]$. The applied stimulus is expected to yield a short sharp pain that generally lasts just for the duration of the stimulus. However, sometimes pain may continue for a short period of time after removal of the stimulus specially if the patient has sever dentine hypersensitivity $[5,6]$. In view of the fact that, all the evaluation methods are expected to cause pain or discomfort so, it is recommended that one measure should usually be used such as, an air blast from a triple syringe [6]. On other hands, if several stimuli are applied, the least sever stimulus should be always performed first to avoid a negative impact on the results of the stimulation. Furthermore, the interval between stimulus applications should be sufficient to prevent interactions between both stimuli [39,42].

\section{Diagnosis of DHS and Differential Diagnosis}

Since DHS is based on a diagnosis of exclusion, the clinician should use all his skills in gaining the necessary information relating to a patient's history screening, identification of etiologic and predisposing factors, particularly dietary and oral hygiene habits associated with erosion and abrasion [9]. This is in order to exclude other dental conditions that present with dental pain similar to that of DHS and to make a definite diagnosis of DHS and ultimately to a successful treatment strategy [52].

In the clinical history investigation, a verbal screening is recommended during which the patient is asked about the time of the start of the disease, the site, the intensity, and the stability of the pain and about the factors that reduce or increase the intensification of the disease $[6,42,52]$. Moreover, the patients should be asked if the symptoms are present during oral hygiene procedures or following previous dental therapies like professional tooth cleaning, scaling, and other periodontal treatments; vital tooth bleaching and restorative procedures [6]. Also, the dental professionals should ask and look for personal behavior patterns such as extrinsic and intrinsic acids, consumption of high-acid drinks or food, and overzealous dental hygiene $[4,6,42]$.

In patients with suspected DHS due to positive findings in the screening and history, the thorough differential diagnosis is very important to eliminate all other forms of orofacial pain, including pulpal inflammation, periodontal pain, cracked tooth syndrome, insufficient margins of restorations, atypical odontalgia etc. All differential diagnosis must be excluded, before the diagnosis of DHS is definitely confirmed [42,50]. This simple strategy should capture the majority of DHS sufferers, thus enabling the dental professional to manage the problem more thoroughly.

The clinical examination should include an accurate assessment to identify all sensitive teeth and to confirm clinical signs associated with the definition of dentin hypersensitivity such as dental erosion, gingival recession, and exposed cervical dentin $[5,6]$. This is in order to reconstruct the stimulating factors and to determine the degree of pain of the patient $[30,54]$. It should include different triggers $[6,30,52]$ such as:

i. Thermal and evaporative stimuli like a short blast of cold air from the 3-in-1syringe, ice stick, ethyl chloride or cold water testing. A useful tip in identifying some of these conditions has been suggested, such as, the application of a varnish on the exposed root surface with the clinician evaluating the severity of the problem before and after application with an air blast from a dental air syringe [53].

ii. Mechanical/tactile stimuli as running a sharp explorer over the area of exposed dentine in a mesio-distal direction, scaling procedures, single-tufted brush, or using mechanical pressure stimulators.

iii. Chemical (osmotic) stimuli such as using hypertonic solution as sodium chloride, glucose, or sucrose. 
iv. Electrical stimulation such as using electrical pulp testers and dental pulp stethoscope.

The application of a controlled stimulus would be predicted to result in a short sharp pain that generally lasts just for the duration of the stimulus. The severity or degree of pain can be quantified either according to categorical scale such as slight, moderate or pain or using a visual analogue scale [54]. On the other hands, some other forms of diagnostic tests such as percussion, palpitation, radiographic investigation, vitality test, pushing a wood stick and trans illumination tests are performed for diagnosis and exclusion other possible causes of dental pain as pulpitis, periodontal involvement, a fracture or cracked tooth and pain associated with recent restorations [1,30,53,55]. A useful guide for distinguishing the different types of dental pain which may lead to a correct diagnosis of DHS has been suggested in Table $1[55,56]$.

Therefore, it is very essential to record all the characteristic data obtained from patient's medical history and clinical examination to assess DHS and to rule out all other causes of the dental pain which need a variety of treatment options for resolution.

\section{Management Strategy of DHS}

The clinical management of DHS depends mainly on identification and elimination of the causative and predisposing factors, which could lead to lesion localization and lesion initiation in order to prevent the occurring or even reoccurring of the condition $[6,50]$.

\section{Control measure for prevention of DHS and removal of the etiological factors}

Various studies suggested that the dental practitioner should advice his/her patient to follow certain preventive measures to reduce both the frequency and intensity of DHS episodes. These measures are considered as self-care strategies.

i. Avoid faulty tooth brushing to lower the risk of gingival recession and abrasion of exposed cementum and dentin $[4,17]$. It includes

- Not to use a hard tooth brush use only a toothbrush with soft filaments.

- Avoid using of an excessive pressure or force during brushing.

- Brushing time should not be extended for prolonged period of time.

- Excessive scrubbing at the cervical part of the tooth that damages to the supporting structures and causes gingival recession should be avoided.

- Not to use large amounts of dentifrice or reapplying it during brushing.

- Avoid using a highly abrasive tooth powder or paste.

ii. The use of an additional aids [17,51], such as:

- Desensitizing dentifrices containing an active agent potassium salts such as potassium nitrate, potassium chloride or potassium citrate, where the potassium ions can decrease the excitability of A fibers, which surround the odontoblasts resulting in a significant reduction tooth sensitivity.

- Remineralizing toothpastes containing sodium fluoride and calcium phosphates.

\begin{tabular}{|c|c|}
\hline $\begin{array}{l}\text { Conditions to be excluded in the diagnosis } \\
\text { of DHS }\end{array}$ & Confounding features \\
\hline Dental caries & $\begin{array}{l}\text { Greatest degree of sensitivity experienced when dental caries passes the dental- enamel junction. As caries } \\
\text { penetrates further into the tooth sensitivity lessens until pulp becomes involved [57]. }\end{array}$ \\
\hline Cracked tooth syndrome & $\begin{array}{l}\text { Sharp intermittent pain elicited on biting as the occlusal force increases and the relief of pain occurs once the pressure } \\
\text { is withdrawn using bite test, a tooth sleuth, or tapping of a single cusp [57]. }\end{array}$ \\
\hline Traumatized teeth or chipped teeth & $\begin{array}{l}\text { a. Enamel fracture induces a superficial, rough edges that may cause tongue or lip irritation, but there is no sensitivity or pain complain by the } \\
\text { patient [57]. } \\
\text { b. Enamel and dentin fracture induces rough edge on the tooth and it is usually accompanied by tooth sensitivity or pain [57]. }\end{array}$ \\
\hline Pulpitis & $\begin{array}{l}\text { a. Reversible pulpitis induces sharp pain that provoked by hot, cold, or sweet. The pain disappears after stimulus removal [58]. } \\
\text { b. Irreversible pulpitis elicits severe, sharp, throbbing, intermittent or continuous pain that may keep the patient awake at night. Pain is } \\
\text { provoked by hot, chewing, Iying flat and it persists after a stimulus removal. Dull and throbbing pain denoted abscessed or non- vital tooth, } \\
\text { necrosis, and pain irradiating from other sites in the mouth which denoted as referred pain [58]. }\end{array}$ \\
\hline Lateral periodontal abscess & Deep continuous dull pain increased on biting [58]. \\
\hline Periapical periodontitis & Deep continuous dull pain increased on biting [58]. \\
\hline Pericoronitis & Deep continuous dull pain increased on biting [58]. \\
\hline Bleaching sensitivity & $\begin{array}{l}\text { It is attributed to the penetration of the bleaching agent into the pulp chamber. It takes the form of a reversible pulpitis } \\
\text { [55] }\end{array}$ \\
\hline Tooth grinding (bruxism) & $\begin{array}{l}\text { It is caused by the activation of reflex chewing activity. Pain and sensitivity in the teeth to heat and cold stimuli due } \\
\text { to fattening and wearing of the tooth surface which may reveal the underlying dentine layer. This is accompanied } \\
\text { by muscular facial pain, tension headaches, stiffness and pain in the temporomandibular joint. This is in addition to } \\
\text { enamel micro fractures or broken or chipped teeth depends on the severity and strength of the clenching and grinding } \\
\text { involved in the bruxism [54]. }\end{array}$ \\
\hline Post-operative sensitivity due to & $\begin{array}{l}\text { a. Cavity preparation phase: Pain may due to several possible reasons [55]: } \\
\text { - Heat generation due to lack of adequate cooling during cutting of tooth structure. } \\
\text { - Exerting of excessive pressure during cutting. } \\
\text { - Vibration due to bur eccentricity. } \\
\text { b. Restorative phase: Pain may trigger following placement of a restoration for several possible reasons: } \\
\text { - For resin composite restoration, post-restorative hypersensitivity may be elicited due to leakage, improper bonding procedure, cuspal } \\
\text { - } \quad \text { strain, or fractured restoration. } \\
\text { - cracks, fractured restorations, premature contacts or galvanic stimuli. } \\
\text { - Post-operative hyper sensitivity with resin cements that used for crowns cementation. }\end{array}$ \\
\hline
\end{tabular}

Table 1: Differential diagnosis of dental pain that may exclude during diagnosis of DHS. 
- Mouth rinses and chewing gums that contain potassium or sodium salts.

iii. Avoid excessive flossing or improper use interproximal cleaning devices or toothpicks [6].

iv. Reduce the quantity and the frequency of taking foods containing acids [6].

v. Avoid brushing for at least 30 minutes after taking acidic food or drinks [6].

vi. To take something alkaline or neutral after acidic drink [6].

vii. Maintain good oral hygiene [54].

viii. Wear occlusal splints to minimize tooth wear associated with parafunctional habits like bruxism [57].

If self-care strategy fails to diminish DHS compared with baseline levels, then professional interventions should be started which include professional application of desensitizing agents which based on either occlusive therapies or nerve desensitization strategies [5,17,30,57-59]. The mechanism of occlusive therapies depends on the plugging of the open dentine tubules and formation of a protective layer on the dentin surface, so a reduction in dentin permeability as well as sensitivity occurs with occlusion of dentine tubules. This could be achieved through:

i. The use of varnish, calcium compounds, fluoride compounds with or without iontophoresis, oxalates or Pro-Argin technology leads to precipitation of a dentin-like mineral [60-63].

ii. The application of strontium chloride, formaldehyde or glutaraldehyde leads to formation of salivary protein precipitants in dentine tubule. These agents are very strong tissue fixatives; they should be used with extreme caution to ensure they do not come in contact with the vital gingival tissues [64].

iii. The use of anti-inflammatory agents such as corticosteroids which presumed to induce mineralization leading to tubule occlusion [65].

iv. The application of adhesive resin materials which seal the dentine tubules by forming a hybrid layer and resinous tags [54]. A new generation of dentin bonding agent contains desensitizers are introduced with only purpose of treating DHS. These new products cause coagulation and precipitation of serum proteins inside dentine tubules beside formation of resinous tags [66]. Generally, this technique is used for specific and localized cases of dentin hypersensitivity rather than generalized one [67].

v. The use of bioactive glass which has shown to form an appetite layer that occludes the dentine tubules due to the presence of silica in its composition which acts as site for precipitation of calcium and phosphates [68].

vi. Laser application which was thought to work through either recrystallization of dentin producing a glazed, nonporous surface that partially or totally obliterate dentine tubules or by affecting the neural transmission through coagulation of proteins in the dentine fluid and hence reduce permeability and block fluid movement [69].

vii. The use of Heal Ozone treatment where the ozone penetrates the exposed tubules eliminating bacterial contamination and allowing mineral ingress and subsequent sealing of the dentine tubules [70].
On other hand, nerve desensitization strategy by potassium salts depends on blocking of the synapse between the nerve cells by potassium ions, which will reduce the nerve excitation and the pain associated with it $[71,72]$.

Other treatment options which are considered invasive solutions and as a last option for a tooth which does not respond to other desensitizing protocols are:

i. Use of restorative material such as glass ionomer, and composite resins restorations for situations where there has been significant loss of cervical tooth structure [13]

ii. Periodontal surgery including free gingival grafts, lateral sliding grafts, connective tissue and coronally repositioned flaps can be performed to cover exposed root surface [13].

iii. If the symptoms still persists, the offending tooth is either root canal treated or extracted [57].

\section{Conclusion}

Clinically, DHS is a relatively common and significant dental problem for which patients look for treatment and visit dental clinics. There are many treatment modalities for DHS which the clinician may find successful in relieving the pain of DHS. The dental practitioner should first identify the causative or predisposing factor after taking a thorough history before the treatment plan is designed. The treatment strategy of the DHS should be begun with prevention, selfcare management and later may be supplemented with professional interventions depending on the severity of the case.

\section{References}

1. Dowell P, Addy M (1983) Dentine hypersensitivity-a review. Aetiology, symptoms and theories of pain production. J Clin Periodontol 10: 341-350.

2. Amarasena N, Spencer J, Ou Y, Brennan D (2011) Dentine hypersensitivity in a private practice patient population in Australia. J Oral Rehabil 38: 52-60.

3. Que K, Ruan J, Fan X, Liang X, Hu D (2010) A multi-centre and cross-sectional study of dentine hypersensitivity in China. J Clin Periodontol 37: 631-637.

4. Addy M (2002) Dentine hypersensitivity: new perspectives on an old problem Int Dent J 52: 367-375

5. Porto IC, Andrade AK, Montes MA (2009) Diagnosis and treatment of dentinal hypersensitivity. J Oral Sci 51: 323-332.

6. Gillam D, Chesters R, Attrill D, Brunton P, Slater M, et al. (2013). Dentine hypersensitivity-guidelines for the management of a common oral health problem. Dent Update 40: 514-524.

7. Dowell $P$, Addy M, Dummer $P$ (1985) Dentine hypersensitivity: aetiology, differential diagnosis and management. Br Dent J 158: 92-96.

8. Holland GR, Narhi MN, Addy M, Gangarosa L, Orchardson R (1997) Guidelines for the design and conduct of clinical trials on dentine hypersensitivity. J Clin Periodontol 24: 808-813.

9. Canadian Advisory Board on Dentin Hypersensitivity (2003) Consensus-based recommendations for the diagnosis and management of dentin hypersensitivity. J Can Dent Assoc 69: 221-226.

10. Ide M (1998) The differential diagnosis of sensitive teeth. Dent Update 25: 462 466 .

11. Flynn J, Galloway R, Orchardson R (1985) The incidence of 'hypersensitive' teeth in the West of Scotland. J Dent 13: 230-236.

12. Irwin CR, McCusker $P$ (1997) Prevalence of dentine hypersensitivity in a general dental population. J Ir Dent Assoc 43: 7-9.

13. Bartold PM (2006) Dentinal hypersensitivity: a review. Aust Dent J 51: 212-218.

14. Miglani S, Aggarwal V, Ahuja B (2010) Dentin hypersensitivity: Recent trends in management. J Conserv Dent 13: 218-224. 
15. Kassab MM, Cohen RE (2003) The etiology and prevalence of gingival recession. J Am Dent Assoc 134: 220-225.

16. Colak H, Demirer S, Hamidi M, Uzgur R, Köseoğlu S (2012) Prevalence of dentine hypersensitivity among adult patients attending a dental hospital clinic in Turkey. West Indian Med J 61: 174-179.

17. West NX, Sanz M, Lussi A, Bartlett D, Bouchard P, et al. (2013) Prevalence of dentine hypersensitivity and study of associated factors: a European population-based cross-sectional study. J Dent 41: 841-851.

18. Addy M, Mostafa P, Newcombe RG (1987) Dentine hypersensitivity: the distribution of recession, sensitivity and plaque. J Dent 15: 242-248.

19. Berman LH (1985) Dentinal sensation and hypersensitivity. A review of mechanisms and treatment alternatives. J Periodontol 56: 216-222.

20. Rapp R, Avery JK, Strachan DS (1968) Possible role of the acetylcholinesterase in neural conduction within the dental pulp. In: Finn SB (ed). Biology of the dental pulp organ. University of Alabama Press, Birmingham.

21. Pashley DH (1996) Dynamics of the pulpo-dentin complex. Crit Rev Oral Bio Med 7: 104-133.

22. Irvine JH (1988) Root surface sensitivity: a review of aetiology and management JNZ Soc Periodontol : 15-18.

23. Frank RM, Steuer $P$ (1988) Transmission electron microscopy of the human odontoblast process in peripheral root dentine. Arch Oral Biol 33: 91-98.

24. Brännström M, Aström A (1972) The hydrodynamics of the dentine; its possible relationship to dentinal pain. Int Dent J 22: 219-227.

25. Çolak H (2015) Book Review: Dentine hypersensitivity: developing a personcentered approach to oral health. Br Dent J 218: 617

26. Absi EG, Addy M, Adams D (1987) Dentine hypersensitivity. A study of the patency of dentinal tubules in sensitive and non-sensitive cervical dentine. $J$ Clin Periodontol 14: 280-284.

27. Orchardson R, Cadden SW (2001) An update on the physiology of the dentinepulp complex. Dent Update 28: 200-206, 208-209.

28. Rimondini L, Baroni C, Carrassi A (1995) Ultrastructure of hypersensitive and nonsensitive dentine. A study on replica models. J Clin Periodontol 22: 899-902

29. Chidchuangchai W, Vongsavan N, Matthews B (2007) Sensory transduction mechanisms responsible for pain caused by cold stimulation of dentine in man. Arch Oral Biol 52: 154-160

30. Gillam DG, Orchardson R (2006) Advances in the treatment of root dentin sensitivity: mechanismsand treatment principles. Endod Topics 13: 13-33.

31. Chabanski MB, Gillam DG (1997) Aetiology, prevalence and clinical features of cervical dentine sensitivity. J Oral Rehabil 24: 15-19.

32. Suge T, Kawasaki A, Ishikawa K, Matsuo T, Ebisu S (2006) Effects of plaque control on the patency of dentinal tubules: an in vivo study in beagle dogs. $J$ Periodontol 77: 454-459.

33. Mayhew RB, Jessee SA, Martin RE (1998) Association of occlusal, periodontal, and dietary factors with the presence of non-carious cervical dental lesions. Am J Dent 11: 29-32.

34. Wichgers TG, Emert RL (1997) Dentin hypersensitivity. Oral Health 87: 51-53, $55-6,59$

35. West NX, Lussi A, Seong J, Hellwig E (2013) Dentin hypersensitivity: pain mechanisms and aetiology of exposed cervical dentin. Clin Oral Investig 17 Suppl 1: S9-19.

36. Osborne-Smith KL, Burke FJ, Wilson NH (1999) The aetiology of the noncarious cervical lesion. Int Dent J 49: 139-143.

37. Litonjua LA, Andreana S, Bush PJ, Tobias TS, Cohen RE (2003) Noncarious cervical lesions and abfractions: a re-evaluation. J Am Dent Assoc 134: 845850.

38. Marini MG, Greghi SL, Passanezi E, Sant'ana AC (2004) Gingival recession: prevalence, extension and severity in adults. J Appl Oral Sci 12: 250-255.

39. Gillam DG, Newman HN (1993) Assessment of pain in cervical dentinal sensitivity studies. A review. J Clin Periodontol 20: 383-394.

40. Gillam DG, Bulman JS, Newman HN (1997) A pilot assessment of alternative methods of quantifying dental pain with particular reference to dentine hypersensitivity. Community Dent Health 14: 92-96.
41. Orchardson R, Collins WJ (1987) Thresholds of hypersensitive teeth to 2 forms of controlled stimulation. J Clin Periodontol 14: 68-73.

42. Gernhardt CR (2013) How valid and applicable are current diagnostic criteria and assessment methods for dentin hypersensitivity? An overview. Clin Oral Investig 17 Suppl 1: S31-40.

43. Närhi M, Hirvonen T, Huopaniemi T (1984) The function of intradental nerves in relation to the sensations induced by dental stimulation. Acupunct Electrother Res 9: 107-113.

44. Ide M, Wilson RF, Ashley FP (2001) The reproducibility of methods of assessment for cervical dentine hypersensitivity. J Clin Periodontol 28: 16-22.

45. Huskisson EC (1983) Visual analogue scales. In: R. Melzak (ed). Pain measurement and assessment. Raven Press, New York.

46. Freyd MJ (1923) The graphic rating scale. J Educ Psvchol 14: 83-102.

47. Hicks CL, von Baeyer CL, Spafford PA, van Korlaar I, Goodenough B (2001) The Faces Pain Scale-Revised: toward a common metric in pediatric pain measurement. Pain 93: 173-183.

48. Schiff T, Delgado E, Zhang YP, DeVizio W, Cummins D, et al. (2009) The clinical effect of a single direct topical application of a dentifrice containing $8.0 \%$ arginine, calcium carbonate, and $1450 \mathrm{ppm}$ fluoride on dentin hypersensitivity: the use of a cotton swab applicator versus the use of a fingertip. J Clin Dent 20: $131-136$

49. Petrou I, Heu R, Stranick M, Lavender S, Zaidel L, et al. (2009) A breakthrough therapy for dentin hypersensitivity: how dental products containing $8 \%$ arginine and calcium carbonate work to deliver effective relief of sensitive teeth. J Clin Dent 20: 23-31.

50. Hamlin D, Williams KP, Delgado E, Zhang YP, DeVizio W, et al. (2009) Clinica evaluation of the efficacy of a desensitizing paste containing $8 \%$ arginine and calcium carbonate for the in-office relief of dentin hypersensitivity associated with dental prophylaxis. Am J Dent 22: 16-20.

51. Boiko OV, Baker SR, Gibson BJ, Locker D, Sufi F, et al. (2010) Construction and validation of the quality of life measure for dentine hypersensitivity (DHEQ). J Clin Periodontol 37: 973-980.

52. Gillam DG, Orchardson R, Närhi MVO, Kontturi-Närhi V (2000) Present and future methods for the evaluation of pain associated with dentine hypersensitivity. In: Addy M, Embery G, Edgar WM, Orchardson R (eds). Tooth wear and sensitivity. Martin Dunitz Ltd, London.

53. Gillam DG (2013) Current diagnosis of dentin hypersensitivity in the denta office: an overview. Clin Oral Investig 17 Suppl 1: S21-29.

54. Orchardson R, Gillam DG (2006) Managing dentin hypersensitivity. J Am Dent Assoc 137: 990-998.

55. Gillam DG (2010) Dentin hypersensitivity: an introduction to differentia diagnosis. Dent Pract 48: 34-35.

56. Aghabeigi B (2002) Dental pain. In: Zakrzewska JM (ed). Pain research and clinical management: assessment and management of orofacial pain. Elsevier, Amsterdam.

57. Garg SK, Garg S, Mittal S, Yadav K (2013) Dentin hypersensitivity: an engima Ind J Dent Edu 6: 139-145.

58. Ali S, Farooq I (2013) Dentin hypersensitivity: a review of its etiology, mechanism, prevention strategies and recent advancements in its management. World Journal of Dentistry 4: 188-192.

59. Walters PA (2005) Dentinal hypersensitivity: a review. J Contemp Dent Pract 6: 107-117.

60. Hack GD, Thompson VP (1994) Occlusion of dentinal tubules with cavity varnishes. Arch Oral Biol 39: 149.

61. Levin MP, Yearwood LL, Carpenter WN (1973) The desensitizing effect of calcium hydroxide and magnesium hydroxide on hypersensitive dentin. Oral Surg Oral Med Oral Pathol 35: 741-746.

62. Gangarosa LP, Park NH (1978) Practical considerations in iontophoresis of fluoride for desensitizing dentin. J Prosthet Dent 39: 173-178.

63. Singh S (2013) Pro-Argin: a breakthrough technology for dentin hypersensitivity treatment. Int J Sci Stu 1: 133-137.

64. Addy M, Mostafa P (1988) Dentine hypersensitivity. I. Effects produced by the uptake in vitro of metal ions, fluoride and formaldehyde onto dentine. $\mathrm{J}$ Ora Rehabil 15: 575-585. 
65. Scherman A, Jacobsen PL (1992) Managing dentin hypersensitivity: what treatment to recommend to patients. J Am Dent Assoc 123: 57-61.

66. Qin C, Xu J, Zhang Y (2006) Spectroscopic investigation of the function of aqueous 2-hydroxyethylmethacrylate/glutaraldehyde solution as a dentin desensitizer. Eur J Oral Sci 114: 354-359.

67. Addy M, Dowell P (1983) Dentine hypersensitivity--a review. Clinical and in vitro evaluation of treatment agents. J Clin Periodontol 10: 351-363.

68. Forsback AP, Areva S, Salonen JI (2004) Mineralization of dentin induced by treatment with bioactive glass S53P4 in vitro. Acta Odontol Scand 62: 14-20.
69. Talesara K, Kulloli A, Shetty S, Kathariya R (2014) Evaluation of potassium binoxalate gel and $\mathrm{Nd}$ :YAG laser in the management of dentinal hypersensitivity: a split-mouth clinical and ESEM study. Lasers Med Sci 29: 61-68.

70. Gupta G, Mansi B (2012) Ozone therapy in periodontics. J Med Life 5: 59-67.

71. Markowitz K, Bilotto G, Kim S (1991) Decreasing intradental nerve activity in the cat with potassium and divalent cations. Arch Oral Biol 36: 1-7.

72. Haywood VB, Caughman WF, Frazier KB, Myers ML (2001) Tray delivery of potassium nitrate-fluoride to reduce bleaching sensitivity. Quintessence Int 32 : 105-109. 